ANL-7335

ANL-7335

Argonne Rational Laboratom

CALCULATIONS ON THE KINETICS OF OXYGEN SOLUTION IN IANTALUM AND NIOBIUM

IN A LIQUID-SODIUM ENVIRONMENT

by

T. F. Kassner and D. L. Smith 


\section{DISCLAIMER}

This report was prepared as an account of work sponsored by an agency of the United States Government. Neither the United States Government nor any agency Thereof, nor any of their employees, makes any warranty, express or implied, or assumes any legal liability or responsibility for the accuracy, completeness, or usefulness of any information, apparatus, product, or process disclosed, or represents that its use would not infringe privately owned rights. Reference herein to any specific commercial product, process, or service by trade name, trademark, manufacturer, or otherwise does not necessarily constitute or imply its endorsement, recommendation, or favoring by the United States Government or any agency thereof. The views and opinions of authors expressed herein do not necessarily state or reflect those of the United States Government or any agency thereof. 


\section{DISCLAIMER}

Portions of this document may be illegible in electronic image products. Images are produced from the best available original document. 
The facilities of Argonne National Laboratory are owned by the United States Government. Under the terms of a contract (W-31-109-Eng-38) between the U. S. Atomic Energy Commission, Argonne Universities Association and The University of Chicago, the University employs the staff and operates the Laboratory in accordance with policies and programs formulated, approved and reviewed by the Association.

\section{MEMBERS OF ARGONNE UNIVERSITIES ASSOCIATION}

The University of Arizona Carnegie Institute of Technology Case Institute of Technology The University of Chicago University of Cincinnati Illinoie Institute of Technology University of Illinois Indiana University Iowa State University
The University of Iowa Kansas State University The University of Kansas Loyola University Marquette University Michigan State University The Universlly of Michigan. University of Minnesota University of Missouri
Northwestern University University of Notre Dame The Ohio State University Purdue University Saint Louis University Washington University Wayne State University The University of Wisconsin

\section{LEGAL NOTICE}

This report was prepared as an account of Government sponsored work. Neither the United States, nor the Commission, nor any person acting on behalf of the Commission:

A. Makes any warranty or representation, expressed or implied, with respect to the accuracy, completeness, or usefulness of the information contained in this report, or that the use of any information, apparatus, method, or process disclosed in this report may not infringe privately owned rights; or

B. Assumes any liabilities with respect to the use of, or for damages resulting from the use of any information, apparatus, method, or process disclosed in this report.

As used in the above, "person acting on behalf of the Commission" includes any employee or contractor of the Commission, or employee of such contractor, to the extent that such employee or contractor of the Commission, or employee of such contractor prepares, disseminates, or provides access to, any information pursuant to his employment or contract with the Commission, or his employment with such contractor.

Printed in the United States of America

Available from

Clearinghouse for Federal Scientific and Technical Information

National Bureau of Standards, U. S. Department of Commerce

Springfield, Virginia 22151

Price: Printed Copy $\$ 3.00$; Microfiche $\$ 0.65$ 
T. F. Kassner and D. L. Smith

\section{Metallurgy Division}

Program 8.2.4

\section{September 1967}

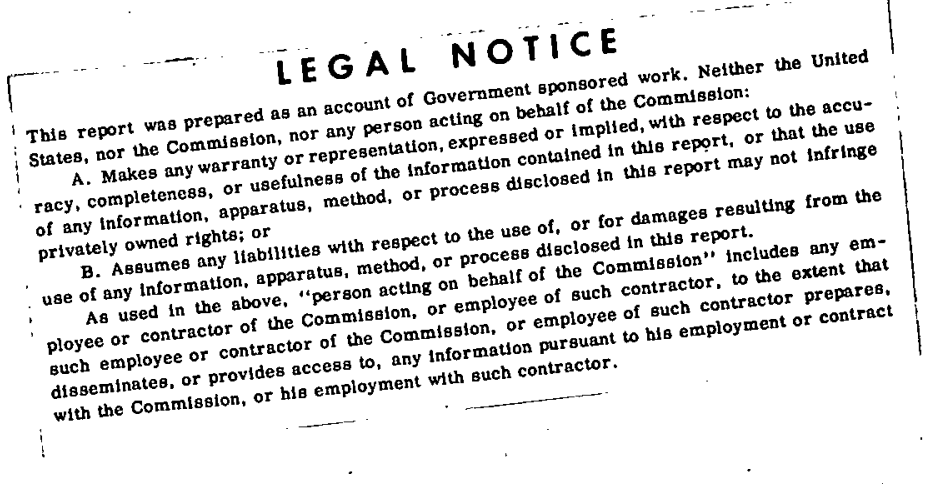




\section{TABLE OF CONTENTS}

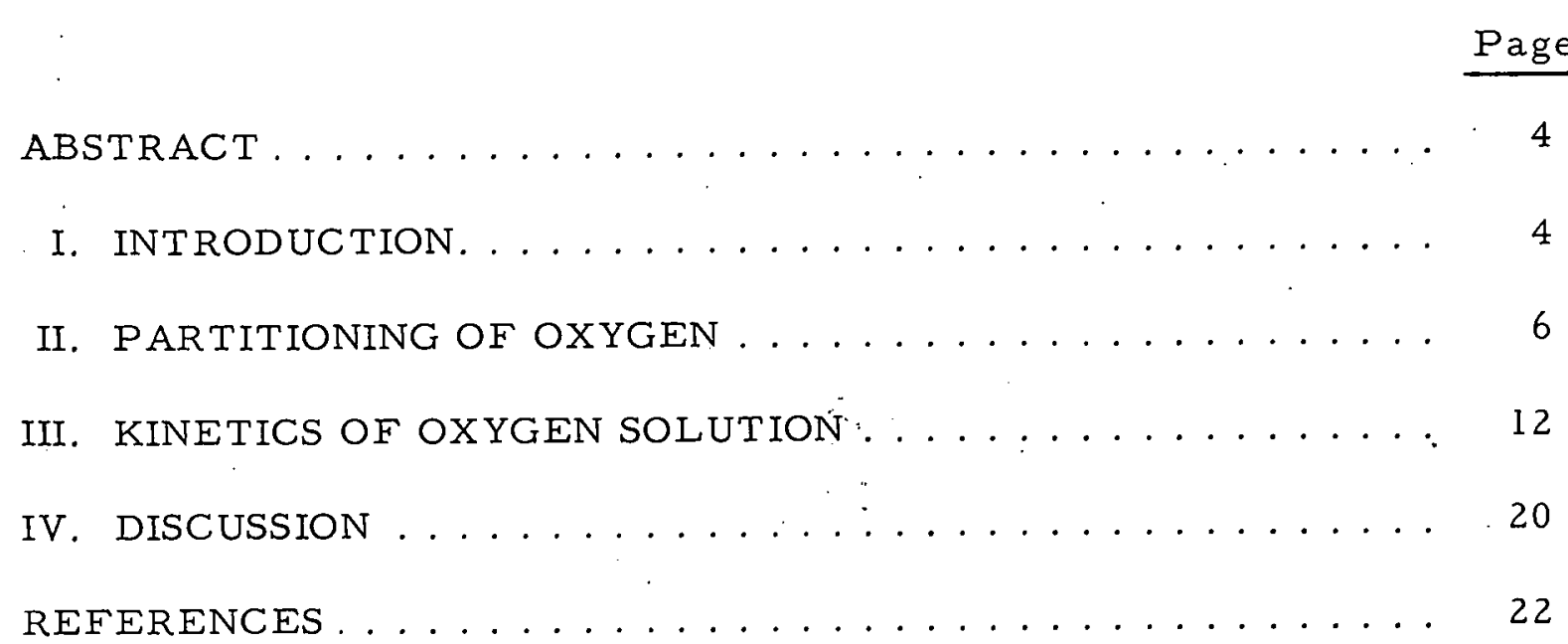




\section{LIST OF FIGURES}

No.

Title

Page

1. Temperature Dependence of the Solubility of Oxygen in Liquid

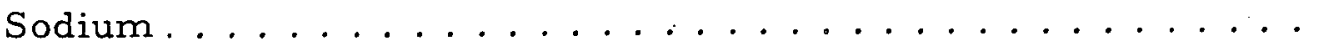

2. Temperature Dependence of the Solubility of Oxygen. in

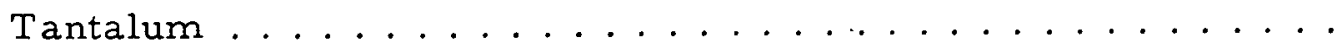

3. Temperature Dependence of the Solubility of Oxygen. in Niobium . . . . . . . . . . . . . . . . . . .

4. Temperature Dependence of the Distribution Coefficient of Oxygen between Tantalum and Sodium, and Niobium and

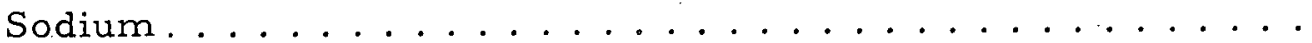

5. Temperature Dependence of the $\mathrm{Ta}$ (O sat) $-\underline{\mathrm{O}} \mathrm{Na}-\mathrm{Ta} \mathrm{O}_{2} \mathrm{O}_{5}$

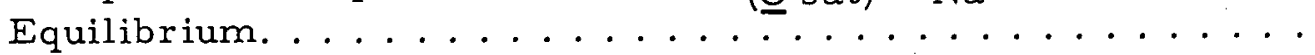

6. Temperature Dependence of the $\mathrm{Nb}$ ( $\mathrm{O}$ sat) $-\underline{\mathrm{O}}_{\mathrm{Na}}-\mathrm{NbO}$ and $\mathrm{NbO}-\mathrm{O} N a-\mathrm{NbO}_{2}$ Equilibria . . . . . . . . . . . . . . . 10

7. Temperature Dependence of the Diffusion Coefficient of

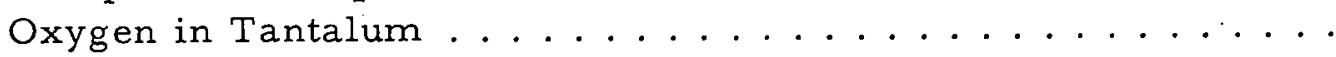

8. Temperature Dependence of the Diffusion Coefficient of

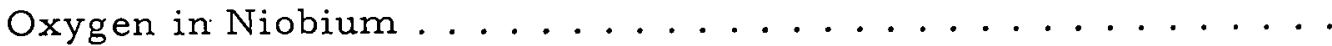

9. Temperature Dependence of the Parabolic Rate Constant for Oxygen Solution in Tantalum with Zero Initial Oxygen Content .

10. Temperature Dependence of the Parabolic Rate Constant for Oxygen Solution in Tantalum with Initial Oxygen Contents of

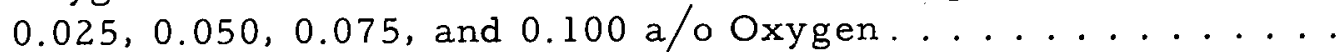

11. Effect of Initial Oxygen Concentration in Tantalum on the Parabolic Rate Constant for Oxygen Solution in Tantalum at $500,600,700$, and $800^{\circ} \mathrm{C} \ldots \ldots \ldots$

12. Temperature Dependence of the Parabolic Rate Constant for Oxygen Solution in Niobium with Zero Initial Oxygen Content ..

13. Temperature Dependence of the Parabolic: Rate Constant for. Oxygen Solution in Niobium with Initial Oxygen Contents of

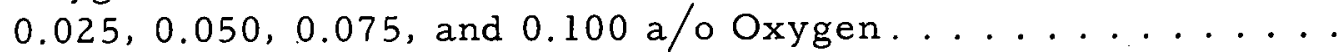

14. Effect of Initial Oxygen Concentration in Niobium on the Parabolic Rate Constant for Oxygen Solution in Niobium at $500,600,700$, and $800^{\circ} \mathrm{C} \ldots \ldots \ldots \ldots$ 


\title{
CALCULATIONS ON THE KINETICS OF OXYGEN SOLUTION IN TANTALUM AND NIOBIUM IN A LIQUID-SODIUM ENVIRONMENT
}

by

T. E. Kassner and D. L. Smith

\begin{abstract}
The parabolic rate constants for oxygen solution in tantalum and niobium in low-oxygen sodium have been calculated as a function of temperature, oxygen concentration in sodium, and initial oxygen concentration in the refractory metals. The results were obtained for temperatures between 500 and $800^{\circ} \mathrm{C}$, oxygen concentrations in sodium from 1 to $20 \mathrm{ppm}$, and initial oxygen concentrations in the refractory metals from 0 to $0.10 \mathrm{a} / 0$ oxygen. The activation energy for: the solution process was less than the activation energy for oxygen.diffusion in the refractory metals. At low oxygen concentrations in sodium, plots of the logarithm of the parabolic rate constants versus reciprocal temperature were nonlinear for low initial oxygen concentrations in the refractory metals. Also, on the basis of phase equilibria calculations in the $\mathrm{Ta}-\mathrm{O}-\mathrm{Na}$ and $\mathrm{Nb}-\mathrm{O}-\mathrm{Na}$ systems, we have predicted the conditions of temperature and oxygen concentration in sodium over which the phases tantalum and $\mathrm{Ta}_{2} \mathrm{O}_{5}$, and niobium, $\mathrm{NbO}$, and $\mathrm{NbO}_{2}$ are thermodynamically stable in sodium.
\end{abstract}

\section{INTRODUCTION}

Those engaged in sodium technology know that predictive capability in the area of sodium corrosion is very limited. Most of the existing knowledge has come from empirical tests designed primarily to give results on specific metals or alloys under the test conditions. In many: instances, because of the contemporary "state-of-the-art," the workwas performed under inadequately defined experimental conditions, and consequently its usefulness in establishing a predictive capability is limited. The results have indicated that impurities such as oxygen, nitrogen, and carbon have a significant effect on the corrosion and mechanical properties of structural materials in alkali-metal-cooled reactors; however, the mechanisms by which these impurities interact are not well understood. Rapid progress in this important area will require a more fundamental knowledge of the chemistry of sodium-impurity systems. For the present, careful control of experimental conditions, coupled with accurate measurements of impurity concentrations in sodium, is a minimum requirement. 
The refractory metals have practical interest because of their favorable high-temperature properties. In addition, these metals are a good choice to test corrosion models based upon impurity reactions for the following reasons: First, from an experimental standpoint, the reaction rate for the material should be highly dependent on impurity concentrations in liquid sodium. Second, in view of the relatively high oxygen-diffusion rates and oxygen distribution coefficients for the refractory metals, it appears that the overall process of oxygen solution in the solid can occur rapidly enough for diffusional processes in the liquid to be rate controlling. This affords the opportunity to experimentally observe a shift in reaction control (e.g., from liquid diffusion to mixed reaction control), which can be of great use in deducing reaction mechanisms.

Before initiating experimental studies, we made preliminary calculations, based on thermodynamic data, to determine the degree to which system variables must be controlled to obtain meaningful results. We also explored the range over which the parameters should be varied and the types of reactions anticipated under the various conditions. In this report, we have restricted our attention to interactions of oxygen in sodium with niobium and tantalum. This restriction was imposed mainly by a present lack of free-energy data for the appropriate metal-impurity compounds - and solubility data for the other impurity elements in the refractory metals and in sodium. The investigation of reaction processes in a system with more than one impurity (e.g., carbon and oxygen) may have greater practical implications, but is even more intractable at present for the reasons cited previously.

A number of heterogeneous processes are possible in refractory metal-sodium systems when additional components such as oxygen, nitrogen, and carbon are present at low concentrations. For example, in the niobiumoxygen-sodium system, we can consider the following processes: (1) dissolution of niobium in sodium, (2) solution or dissolution of oxygen in niobium, (3) formation of a protective oxide film on niobium ( $\mathrm{NbO}$ or $\mathrm{NbO} / \mathrm{NbO}_{2}$ ) with oxygen solution in the metal, (4) nonprotective film formation with metal removal by oxide spallation, and (5) complex oxide formation (sodium niobate).

Under a given set of experimental conditions (i.e., temperature, total pressure, and oxygen activity of the sodium), more than one of the above processes may decrease the free energy of the system. However, depending upon the rates of interfacial reactions and diffusional transport of reacting species in both the liquid and solid phases, one process may predominate.

From thermodynamic data for the binary. refractory metal-oxygen and sodium-oxygen systems, we can predict the range of temperature and oxygen concentration of the sodium over which the phases niobium, NbO, 
and $\mathrm{NbO}_{2}$ can exist. In addition, when appropriate diffusion data for oxygen in the refractory metal and for the refractory metal in liquid sodium are available, the kinetics of relatively simple processes, such as oxygen solution in the solid and dissolution of the solid in sodium, can be predicted from analytical solutions to transport equations under boundary conditions wherein surface equilibria are assumed. Calculations of this type yield an upper limit for the magnitude of the rates for the above processes.

The results of calculations for the partitioning of oxygen in the niobium-sodium and tantalum-sodium systems have been used to determine the oxygen concentration in sodium required for oxide film formation in both systems as a function of temperature. Also, the kinetics of oxygen solution in niobium and tantalum have been predicted for the limiting case where oxygen transport in the liquid is not controlling, film formation does not occur, and there is negligible dissolution of the refractory metal in the liquid. These conditions can be approximated in an isothermal closed system with a fixed low oxygen concentration in the sodium.

\section{PARTITIONING OF OXYGEN}

The distribution coefficient, which is the equilibrium ratio of oxygen concentration in the refractory metal to oxygen concentration in sodium, is derived by equating the partial molal free energies of oxygen in the two metals. Tocalculate the distribution coefficients, we must know the standard free energy of formation of the oxide phase in equilibrium with the oxygen-saturated metal and the equilibrium solubility of oxygen, as a function of temperature for each metal.

We surveyed the literature to obtain free-energy and solubility data for the systems of interest. Figures $1-3$ show the equations we determined

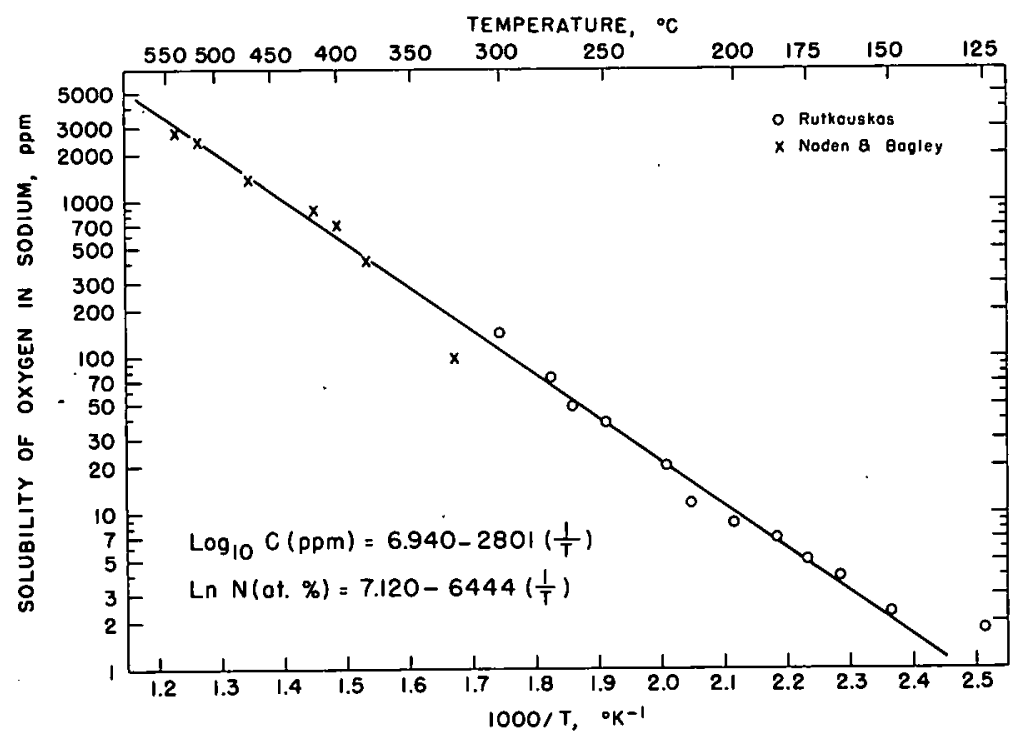

Fig. 1. Temperature Dependence of the Solubility of Oxygen in Liquid Sodium ${ }^{1,2}$ 


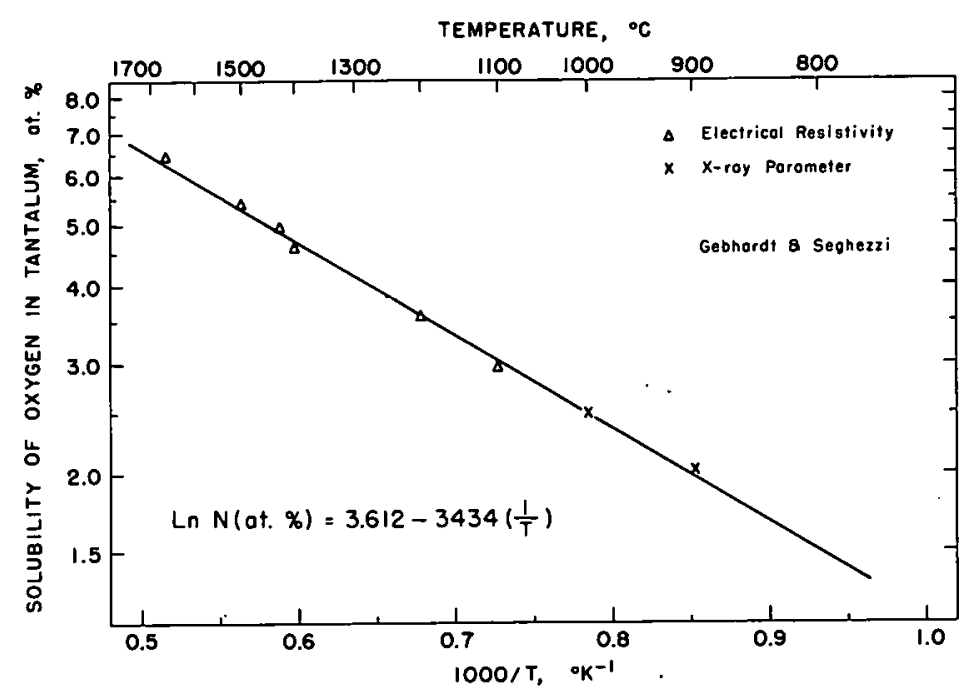

Fig. 2. Temperature Dependence of the Solubility of Oxygen in Tantalum ${ }^{3}$.

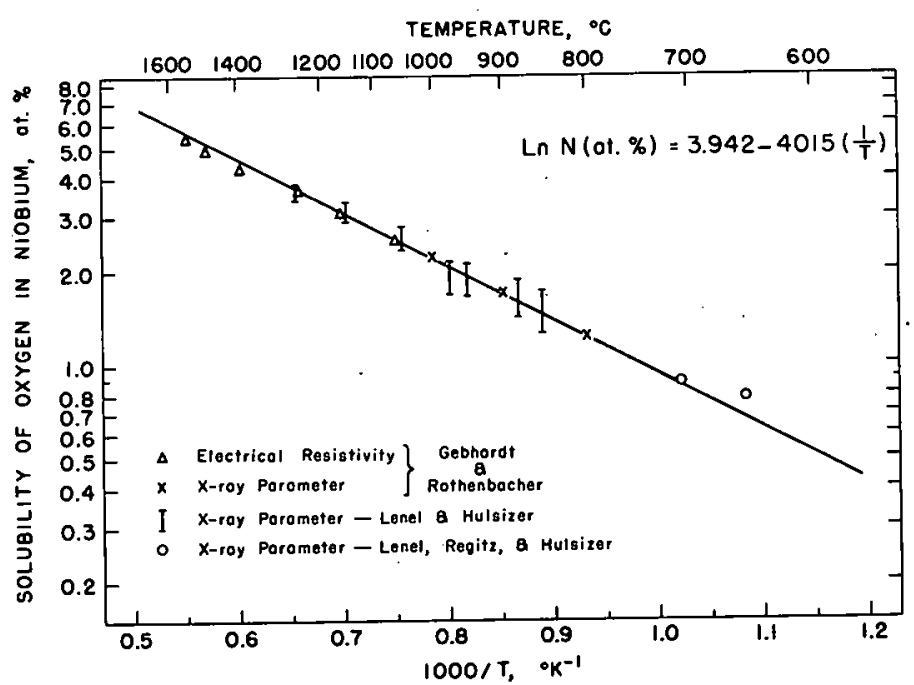

Fig. 3. Temperature Dependence of the Solubility of Oxygen in Niobium ${ }^{4-6}$

and the data we believe to be most reliable for the solubility of oxygen in each of the three metals. The low-temperature data for the solubility of oxygen in sodium are the results of a recent study ${ }^{1}$ and are considerably lower than values previously reported. The standard free energies of formation for the oxides (calories per mole of oxygen) were obtained from Bureau of Mines Bulletin 542 for sodium oxide $\left(\mathrm{Na}_{2} \mathrm{O}\right)$,

$$
\Delta \mathrm{F}_{\mathrm{Na}_{2} \mathrm{O}}^{\circ}=-100,120+34.60 \mathrm{~T} \text {, }
$$

and from Worrell's ${ }^{7}$ data for tantalum oxide $\left(\mathrm{Ta}_{2} \mathrm{O}_{5}\right)$ and niobium oxide (NbO),

$$
\Delta \mathrm{F}_{1 / 5}^{\circ} \mathrm{Ta}_{2} \mathrm{O}_{5}=-96,320+19.44 \mathrm{~T}
$$


and

$$
\Delta \mathrm{F}_{\mathrm{NbO}}^{\circ}=-100,350+21.42 \mathrm{~T} \text {. }
$$

Although several oxides of tantalum have been reported in the literature, ${ }^{8}$ there is evidence $e^{9-11}$ that only $\mathrm{Ta}_{2} \mathrm{O}_{5}$ is stable. Worrell has also reported that no extraneous lines were observed in X-ray diffraction patterns of $\mathrm{Ta}-\mathrm{Ta}_{2} \mathrm{O}_{5}$ and $\mathrm{Nb}-\mathrm{NbO}$ electrodes used in the thermodynamic studies at temperatures between 1050 and $1300^{\circ} \mathrm{K}$. This observation, plus the stability of emf values found by Worrell, demonstrates that suboxides of tantalum are not stable at these temperatures.

The distribution coefficient for oxygen in the tantalum-sodiumoxygen system is obtained by setting the partial molal free-energy change equal to zero for the reaction

$$
\underline{\underline{O}}_{\mathrm{Na}}=\underline{\underline{O}}_{\mathrm{Ta}} ; \quad \Delta \mathrm{F}=\overline{\mathrm{F}}_{\underline{\mathrm{O}}_{\mathrm{Ta}}}-\overline{\overline{\mathrm{F}}}_{\underline{\mathrm{O}}_{\mathrm{Na}}}
$$

where $\underline{Q}_{\mathrm{Na}}$ denotes oxygen in solution in sodium, and $\underline{\mathrm{O}}_{\mathrm{Ta}}$ is oxygen in solution in tantalum. The free-energy change, $\Delta F$, in Reaction $I$ is equivalent to the sum of the free-energy changes for Reactions II, III, and IV:

$$
\begin{aligned}
& 2 \mathrm{Na}(l)+\underline{O}_{\mathrm{Na}}=\mathrm{Na}_{2} \mathrm{O}_{(\mathrm{s})} \\
& \mathrm{Na}_{2} \mathrm{O}_{(\mathrm{s})}+2 / 5 \mathrm{Ta}(\mathrm{s})=2 \mathrm{Na}(\ell)+1 / 5 \mathrm{Ta}_{2} \mathrm{O}_{5}(\mathrm{~s}) ; \\
& 1 / 5 \mathrm{Ta}_{2} \mathrm{O}_{5}(\mathrm{~s})=2 / 5 \mathrm{Ta}(\mathrm{s})+\underline{\mathrm{O}}_{\mathrm{Ta}} .
\end{aligned}
$$

The free-energy changes for the above three reactions are

$$
\begin{aligned}
& \Delta F_{\text {II }}=-R T \ln \frac{{ }^{a} \underline{Q}(\mathrm{Na})}{{ }^{a} \underline{O}(\mathrm{Na})}, \\
& \Delta F_{\text {III }}=\Delta \mathrm{F}_{1 / 5}^{\circ} \mathrm{Ta}_{2} \mathrm{O}_{5}-\Delta \mathrm{F}^{\circ} \cdot \mathrm{Na}_{2} \mathrm{O}^{\prime}
\end{aligned}
$$

and

$$
\Delta F_{I V}=R T \ln \frac{{ }^{a} \underline{\underline{Q}}(\mathrm{Ta})}{{ }_{\underline{\underline{O}}}^{\mathrm{O}}(\mathrm{Ta})},
$$

where the superscripts on the activities in Eqs. 4 and 6 refer to oxygen in the standard state, i.e., the saturated solution in equilibrium with the lowest oxide phase. When the free-energy expressions in Eqs. 4-6 are inserted into the equilibrium relation, 


$$
\Delta F=\Delta F_{\text {II }}+\Delta F_{\text {III }}+\Delta F_{\text {IV }}=0,
$$

the result is

$$
\frac{{ }^{\mathrm{a}} \underline{\underline{O}}(\mathrm{Ta})}{{ }^{\mathrm{a}} \underline{\mathrm{O}}(\mathrm{Na})}=\frac{\mathrm{a} \underline{\mathrm{Q}}(\mathrm{Ta})}{\mathrm{a}_{\underline{Q}}^{\mathrm{O}}(\mathrm{Na})} \exp \frac{\Delta \mathrm{F}^{\circ} \mathrm{Na}_{2} \mathrm{O}-\Delta \mathrm{F}_{1 / 5}^{\circ} \mathrm{Ta}_{2} \mathrm{O}_{5}}{\mathrm{RT}} .
$$

If the solutions are assumed to obey Raoult's law ( $a_{\underline{O}}=N_{\underline{Q}}$ ), the distribution coefficient in terms of atom fraction of oxygen is

$$
K_{A}=\frac{N_{\underline{Q}}(\mathrm{Ta})}{N_{\underline{O}}(\mathrm{Na})}=\frac{N_{\underline{Q}}^{\mathrm{O}}(\mathrm{Ta})}{N_{\underline{Q}}^{\mathrm{O}}(\mathrm{Na})} \exp \frac{\Delta \mathrm{F}^{\circ} \mathrm{Na}_{2} \mathrm{O}-\Delta \mathrm{F}_{1 / 5}^{\circ} \mathrm{Ta}_{2} \mathrm{O}_{5}}{R T}
$$

When the relations for $\mathrm{N}_{\underline{Q}}^{\mathrm{O}}(\mathrm{Na})$ and $\mathrm{N}_{\underline{\mathrm{O}}}(\mathrm{Ta})$ from Figs. 1 and 2 , respectively, are inserted into Eq. 9 with the free-energy relations from Eqs. 1 and 2 , the distribution coefficient, $\mathrm{K}_{\mathrm{A}}$, becomes

$$
\mathrm{K}_{\mathrm{A}}=\frac{\mathrm{N}_{\underline{O}}(\mathrm{Ta})}{\mathrm{N}_{\underline{O}}(\mathrm{Na})}=61.62 \exp \frac{1098}{\mathrm{~T}} ; \quad \frac{\mathrm{a} / \mathrm{O} \underline{\mathrm{O}} \text { in } \mathrm{Ta}}{\mathrm{a} / \mathrm{O} \underline{\mathrm{O}} \text { in } \mathrm{Na}} .
$$

For comparison with experimental data, it is more convenient to express the distribution coefficient in terms of weight distribution of oxygen:

$$
\mathrm{K}_{\mathrm{W}}=\frac{\mathrm{C}_{\underline{\mathrm{Q}}(\mathrm{Ta})}}{\mathrm{C}_{\underline{\mathrm{O}}(\mathrm{Na})}}=7.829 \exp \frac{1098}{\mathrm{~T}} ; \quad \frac{\text { ppm } \underline{\underline{O}} \text { in } \mathrm{Ta}}{\mathrm{ppm} \underline{\mathrm{O}} \text { in } \mathrm{Na}}
$$

A similar development for the niobium-sodium-oxygen system, with $\mathrm{NbO}$ as the oxide phase in equilibrium with oxygen-saturated niobium, leads to the following expressions for the distribution coefficient in terms of atom fraction and weight distribution:

$$
\begin{aligned}
& K_{A}=\frac{N_{\underline{O}(N b)}}{N_{\underline{Q}(\mathrm{Na})}}=31.63 \exp \frac{2545}{T} ; \quad \frac{a / 0 \underline{\underline{O}} \text { in } \mathrm{Nb}}{\mathrm{a} / \mathrm{O} \underline{\mathrm{Q}} \text { in } \mathrm{Na}} ; \\
& \mathrm{K}_{\mathrm{W}}=\frac{\mathrm{C}_{\underline{\mathrm{O}}(\mathrm{Nb})}}{\mathrm{C}_{\underline{\mathrm{O}}(\mathrm{Na})}}=7.826 \exp \frac{2545}{\mathrm{~T}} ; \quad \frac{\mathrm{ppm} \underline{\mathrm{O}} \text { in } \mathrm{Nb}}{\mathrm{ppm} \underline{\underline{O}} \text { in } \mathrm{Na}} .
\end{aligned}
$$

Figure 4 is a plot of the calculated distribution coefficients, $K_{W}$, as a function of temperature for the two systems. Experimental values for the tantalum-sodium system have been reported by Raines et al.$^{12}$ Their values ranged from 2 to 20 at $500^{\circ} \mathrm{C}$ and 1 to 10 at $650^{\circ} \mathrm{C}$, compared to our calculated values of 32.4 and 25.8 obtained from Eq. 11 for the two 
temperatures. Only qualitative agreement between the experimental and calculated distribution coefficients is expected since the oxygen concentra-

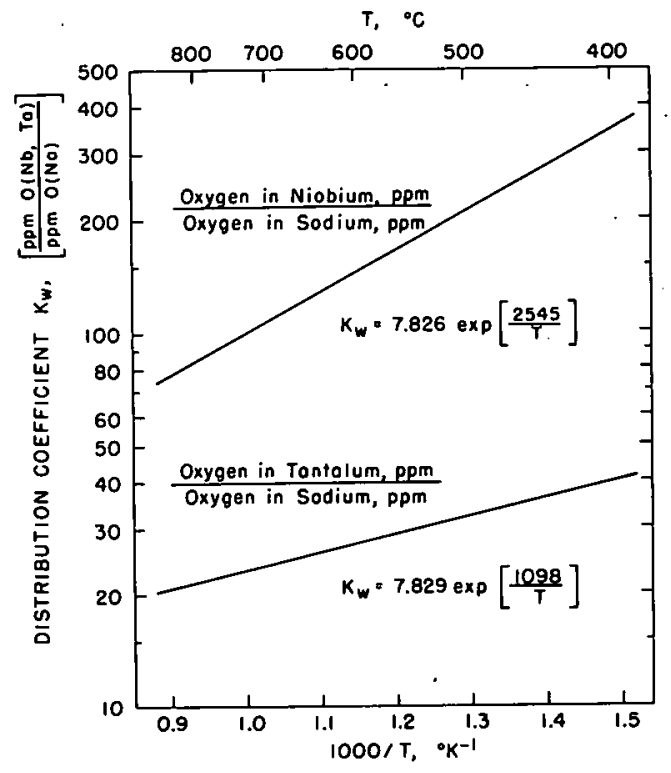

Fig. 4. Temperature Dependence of the Distribution Coefficient of Oxygen between Tantalum and Sodium. and Niobium and Sodium tions in sodium were not determined accurately in those experiments. We have begun experimental work to verify these distribution coefficients under closely controlled conditions.

The oxygen concentration in sodium required for oxide film formation can be predicted by inserting the solubility data for oxygen in tantalum and niobium from Figs. 2 and 3 into the appropriate expres sions for the distribution coefficients, Eqs. 10 and 12, respectively. Figure 5 shows the temperature dependence of the three-phase equilibrium, Ta (O sat) ${ }^{-\mathrm{Ta}_{2} \mathrm{O}_{5}-}$ $\underline{O}_{\mathrm{Na}}$, where the oxygen concentration of sodium is reported in ppm. At $600^{\circ} \mathrm{C}$, no oxide film formation is expected on tantalum exposed to sodium containing less than 23 ppm oxygen.

Figure 6 shows the temperature dependence of the $\mathrm{Nb}$ (O sat)- $\mathrm{NbO}-\underline{\mathrm{O}} \mathrm{Na}$ equilibrium. At a given temperature, the oxygen concentration in sodium required for film formation on niobium is considerably less than that for

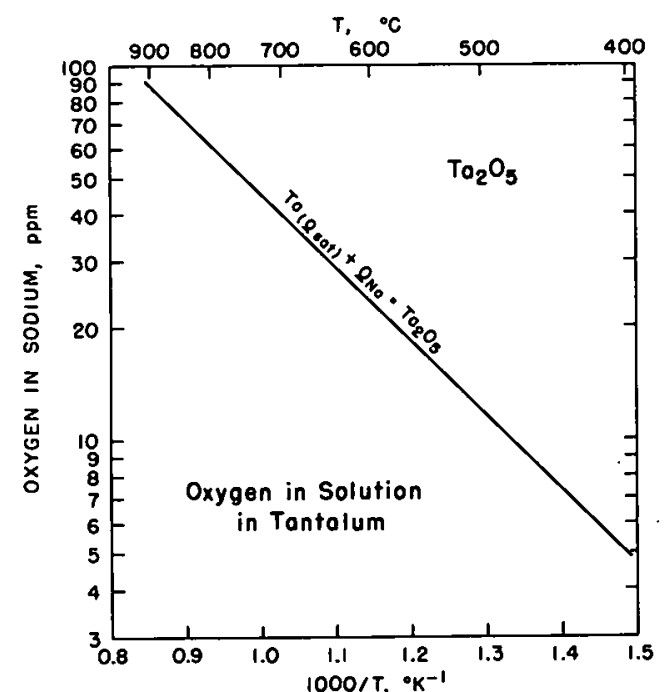

Fig. 5: Temperature Dependence of the $\mathrm{Ta}$ (O sat) $-\underline{\mathrm{ONa}}^{-\mathrm{T} \mathrm{a}_{2} \mathrm{O}_{5}}$ Equilibrium

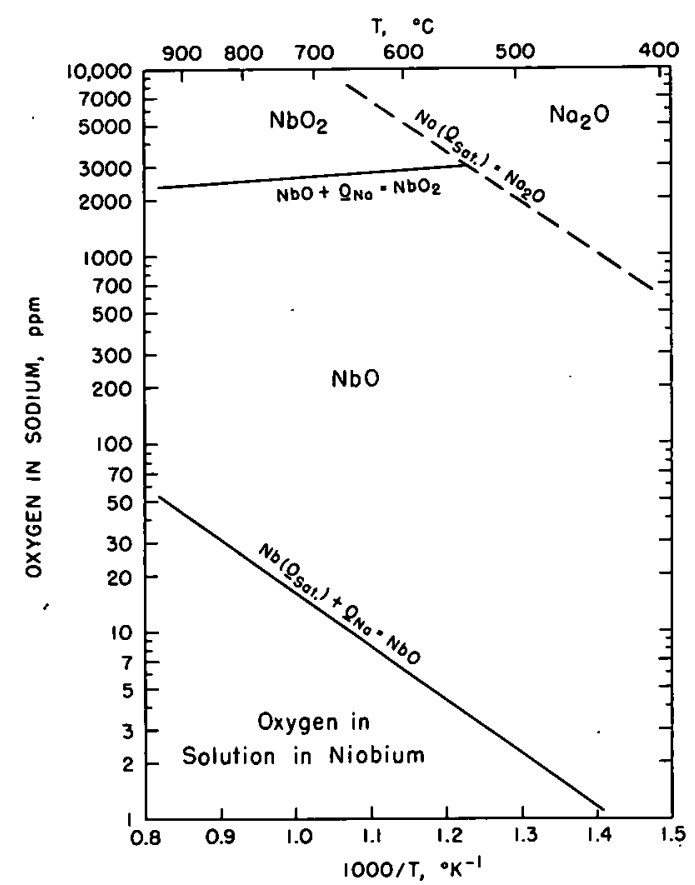

Fig. 6. Temperature Dependence of the $\mathrm{Nb}_{\text {(O sat) }}-\mathrm{O}_{\mathrm{Na}}-\mathrm{NbO}$ and $\mathrm{NbO}-$ $\underline{\underline{O}}_{\mathrm{Na}}-\mathrm{NbO}_{2}$ Equilibria 
tantalum. Only 6 ppm oxygen are required at $600^{\circ} \mathrm{C}$ to form $\mathrm{NbO}$. Evans and Thorley ${ }^{13}$ have reported that niobium has acceptable corrosion behavior in sodium at $\sim 600^{\circ} \mathrm{C}$ when the oxygen content of the sodium is below 5 ppm, whereas above $\sim 5$ ppm the corrosion rate was much higher.

Since niobium forms more than one oxide, the oxygen concentration in sodium at which the second oxide $\left(\mathrm{NbO}_{2}\right)$ is expected to form was also calculated. The net reaction for the formation of niobium dioxide is

$$
\mathrm{NbO}_{(\mathrm{s})}+\underline{\mathrm{O}}_{\mathrm{Na}}=\cdot \mathrm{NbO}_{2}(\mathrm{~s}) ; \quad \Delta \mathrm{F}=\overline{\mathrm{F}}_{\mathrm{NbO}_{2}}-\overline{\mathrm{F}}_{\underline{\mathrm{O}}_{\mathrm{Na}}} \cdot
$$

The free-energy change in this reaction is equal to the sum of the freeenergy changes of the following three reactions:

$$
\begin{aligned}
& 2 \mathrm{NbO}(\mathrm{s})=\mathrm{Nb}(\mathrm{s})+\mathrm{NbO}_{2}(\mathrm{~s}) ; \\
& \mathrm{Nb}(\mathrm{s})+\mathrm{Na}_{2} \mathrm{O}_{(\mathrm{s})}=2 \mathrm{Na}(\ell)+\mathrm{NbO}_{(\mathrm{s})} ; \\
& 2 \mathrm{Na}(\ell)+\underline{\mathrm{O}}_{\mathrm{Na}}=\mathrm{Na}_{2} \mathrm{O}_{(\mathrm{s})} .
\end{aligned}
$$

The free-energy changes for these reactions are

$$
\begin{aligned}
& \Delta F_{\mathrm{VI}}=14,250-4.15 \mathrm{~T}\left(\text { from Worrell }{ }^{7}\right) ; \\
& \Delta F_{\mathrm{V} I I}=\Delta \mathrm{F}^{\circ} \mathrm{NbO}-\Delta \mathrm{F}^{\circ} \mathrm{Na}_{2} \mathrm{O}^{;} \\
& \Delta \mathrm{F}_{\mathrm{II}}=\mathrm{RT} \ln \frac{{ }^{\mathrm{a}} \underline{\mathrm{O}}(\mathrm{Na})}{\mathrm{a}^{\circ} \underline{\mathrm{O}}(\mathrm{Na})} .
\end{aligned}
$$

At equilibrium, the free-energy change for Reaction. $V$ becomes

$$
\Delta F=\Delta F_{V I}+\Delta F_{V I I}+\Delta F_{I I}=0 \text {, }
$$

and with the assumption that oxygen in sodium obeys Raoult's law, the temperature dependence of the $\mathrm{NbO}(\mathrm{s})-\mathrm{NbO}_{2}(\mathrm{~s})-\underline{\mathrm{O}}_{\mathrm{Na}}$ equilibrium is given by

$$
\mathrm{N}_{\underline{O}}(\mathrm{Na})=0.2017 \exp \frac{611}{\mathrm{~T}} ; \quad \text { a/o } \underline{\mathrm{O}} \text { in } \mathrm{Na}
$$

or

$$
\mathrm{C}_{\underline{O}(\mathrm{Na})}=1404 \exp \frac{611}{\mathrm{~T}} ; \quad \text { ppm } \underline{\mathrm{O}} \text { in } \mathrm{Na} .
$$


A plot of Eq. 19.is shown on Fig. 6, along with the temperature dependence of the solubility of oxygen in sodium. The intersection of the $\mathrm{NbO}-\mathrm{NbO}_{2}-$ ONa equilibrium with the $\underline{\mathrm{O}}_{\mathrm{Na}}$ (sat) $-\mathrm{Na}_{2} \mathrm{O}$ equilibrium at $536^{\circ} \mathrm{C}$ represents a four-phase invariant point in the system $\mathrm{NbO}_{-} \mathrm{NbO}_{2}-\mathrm{O}_{\mathrm{Na}}$ (sat) $-\mathrm{Na}_{2} \mathrm{O}$ when the total pressure remains constant.

\section{KINETICS OF OXYGEN SOLUTION}

The kinetics of oxygen solution in tantalum and niobium exposed to sodium can be predicted as a function of oxygen concentration in the sodium, temperature, and initial oxygen concentration in the refractory metal.. The calculations. in this report are applicable to conditions where oxygen diffusion in the solid metal is rate limiting, film formation does not occur, and recession of the solid-liquid interface due to dissolution can be neglected.

The solution to Fick's second law, for diffusion into a semi-infinite slab in which the surface concentration remains constant with time, can be written as

$$
\frac{C(x, t)-C_{0}}{C_{s}-C_{0}}=\operatorname{erfc} \frac{x}{2 \sqrt{D t}}
$$

where

$$
\begin{aligned}
\mathrm{C}(\mathrm{x}, \mathrm{t})= & \text { concentration of oxygen in the sample, } \mathrm{g} \underline{\mathrm{O}} / \mathrm{cm}^{3}, \text { at posi- } \\
& \text { tion } \mathrm{x} \text {, and time } \mathrm{t} ; \\
\mathrm{C}_{\mathrm{s}}= & \text { surface concentration of oxygen in the sample, } \mathrm{g} \mathrm{O} / \mathrm{cm}^{3} ; \\
\mathrm{C}_{0}= & \text { initial uniform concentration of oxygen in the sample, } \\
& \mathrm{g} \mathrm{O} / \mathrm{cm}^{3} ;
\end{aligned}
$$

and

$$
D=\text { diffusion coefficient of oxygen in the sample, } \mathrm{cm}^{2} / \mathrm{sec} \text {. }
$$

The total quantity of oxygen, $M(t)$, diffusing into a slab of area. A in a time $t$ can be obtained by inserting the differential form of Eq. 20 into Fick's first law and integrating the resulting equation. The result is

$$
M(t)=2 A\left(C_{s}-C_{0}\right)\left(\frac{D t}{\pi}\right)^{1 / 2}
$$

The slope of a plot of $[M(t) / A]^{2}$ versus time yields the parabolic rate constant, $K_{p}$ :

$$
K_{p}=\frac{4 D}{\pi}\left(C_{s}-C_{0}\right)^{2} ; \quad g^{2} \underline{O} / \mathrm{cm}^{4}-\mathrm{sec} .
$$




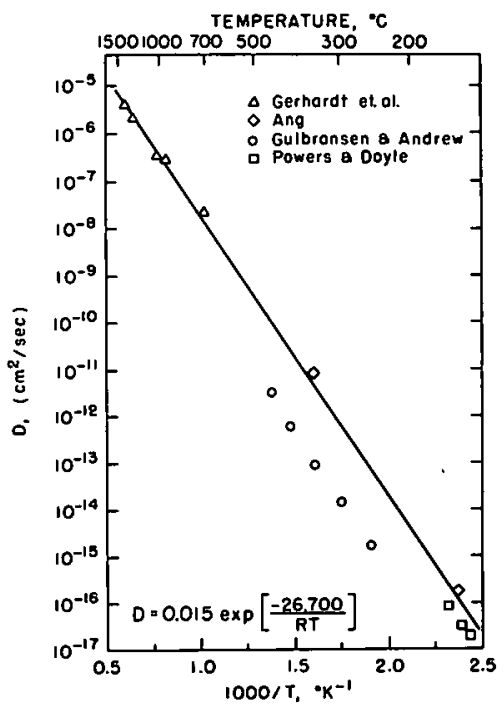

Fig. 7

Temperature Dependence of the Diffusion Coefficient of Oxygen in Tantalum $15-18$
The parabolic rate constants for oxygen solution in tantalum and niobium exposed to sodium have been calculated as a function of temperature for specific oxygen levels in sodium and initial oxygen concentrations in the refractory metals. The diffusion data used in these calculations were obtained from a compilation report by Peterson. ${ }^{14}$ Figure 7 shows the combined data of several authors for the diffusion of oxygen in tantalum. Figure 8 is a curve based on data for diffusion of oxygen in niobium. The values of $C_{\text {s }}$ used in Eq. 22 were obtained as a function of temperature from the partitioning relations (Eqs. 11 and 13) for fixed oxygen concentrations in sodium. These concentrations (ppm $\underline{\mathrm{O}}$ by weight) were converted to the proper units (g의/ $\mathrm{cm}^{3}$ tantalum or niobium) for use in Eq. 22 .

Figure 9 is a plot of $\log K_{p}$ versus reciprocal temperature for zero initial oxygen concentration in the tantalum $\left(C_{0}=0\right)$. The activation energy for oxygen solution in the tantalum can be determined from Eq. 22 by taking the natural logarithm of each term,

$$
\ln K_{p}=\ln \left(\frac{4}{\pi}\right)+\ln D+2 \ln C_{s}, \quad \text { for } C_{0}=0 \text {, }
$$

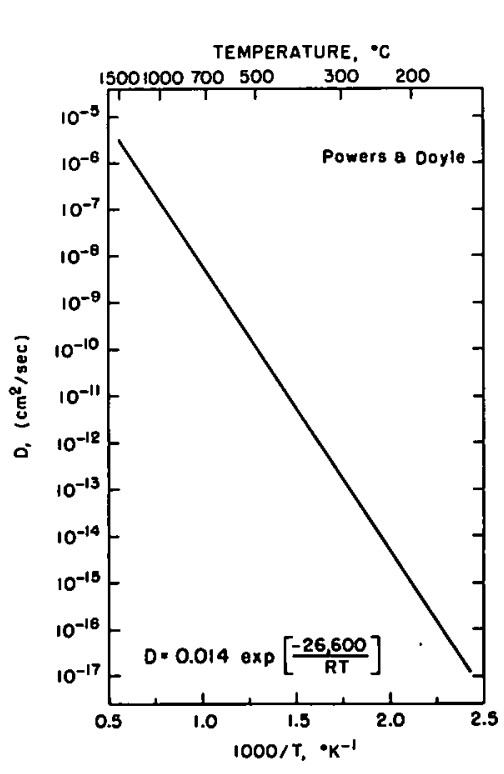

Fig. 8

Temperature Dependence of the Diffusion Coefficient of Oxygen in Niobium ${ }^{19}$

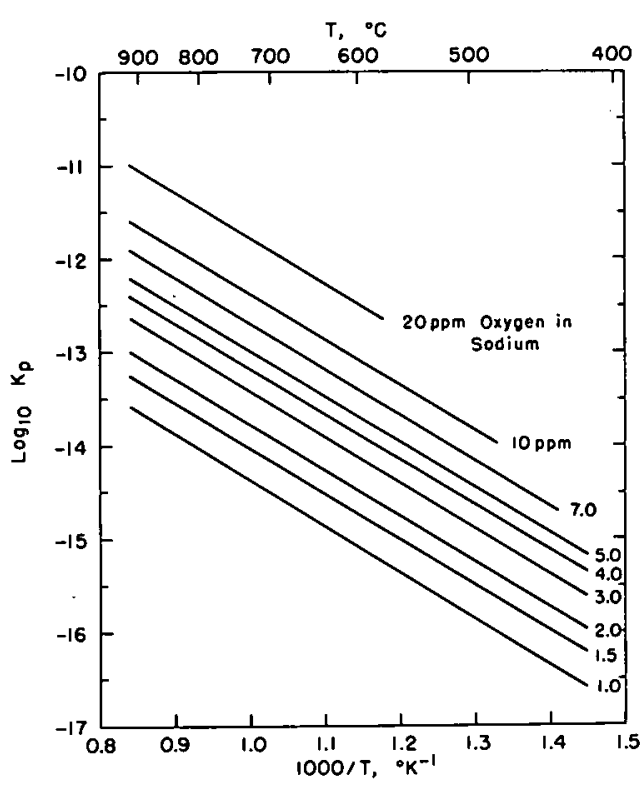

Fig. 9

Temperature Dependence of the Parabolic Rate Constant for Oxygen Solution in Tantalum with Zero Initial Oxygen Content; i.e., $\mathrm{C}_{0}=0$. The parabolic rate constant is in units of $\mathrm{g}^{2} \underline{\mathrm{O}} / \mathrm{cm}^{4}-\mathrm{sec}$. 
multiplying by $-R$, and taking the partial derivative of each term with respect to $(1 / T)$. The result is

$$
-\mathrm{R}\left(\frac{\partial \ln \mathrm{K}_{\mathrm{p}}}{\partial\left(\frac{1}{\mathrm{~T}}\right)}\right)_{\underline{\mathrm{O}}_{\mathrm{Na}}}=-\mathrm{R} \frac{\partial \ln \mathrm{D}}{\partial\left(\frac{1}{\mathrm{~T}}\right)}-2 \mathrm{R}\left(\frac{\partial \ln \mathrm{C}_{\mathrm{s}}}{\partial\left(\frac{1}{\mathrm{~T}}\right)}\right)_{\underline{\mathrm{O}}_{\mathrm{Na}}}
$$

or

$$
Q_{K_{p}}=Q_{D}-2 R\left(\frac{\partial \ln K_{W}}{\partial\left(\frac{1}{T}\right)}\right)_{\underline{o}_{N a}} .
$$

The distribution coefficient, $\mathrm{K}_{W}$, was inserted for $\mathrm{C}_{\mathrm{S}}$ in Eq. 25 since both quantities have the same temperature dependence when the oxygen concentration of the sodium remains constant. An activation energy for the solution process, $Q_{K_{\mathrm{p}}}$, of $22.3 \mathrm{kcal} / \mathrm{mole}$ is obtained from Eq. 25 by inserting the value of $Q_{D} \stackrel{p}{=} 26.7 \mathrm{kcal} /$ mole for oxygen diffusion in tantalum from Fig. 7 and the value of $\partial\left(\ln K_{W}\right) / \partial(1 / T)=1098^{\circ} \mathrm{K}$ from Eq. 11 .

Kofstad ${ }^{20}$ has shown that when tantalum is oxidized in low-pressure oxygen, where the surface concentration remains near saturation, the second term on the right of Eq. 25 is the temperature dependence of the solubility of oxygen in tantalum, $\partial\left[\ln \mathrm{N}_{\mathrm{O}}^{\mathrm{O}}(\mathrm{T} \mathrm{a})\right] / \partial(1 / \mathrm{T})$. When we insert the value of $-3434^{\circ} \mathrm{K}$ from Fig. 2 into Eq. 25 , the activation energy is calculated to be $40.3 \mathrm{kcal} / \mathrm{mole}$. This value agrees well with Kofstad's experimental value of 35 to $40 \mathrm{kcal} /$ mole for oxygen solution in tantalum exposed to 0.01 Torr oxygen pressure. These results indicate that the activation energy for oxygen solution in tantalum exposed to sodium (when $C_{0}=0$ ) is. somewhat less than the activation energy for oxygen diffusion in tantalum and about onehalf the activation energy for oxygen solution in tantalum exposed to lowpressure oxygen.

The effect of the initial oxygen concentration of the tantalum on the parabolic rate constant is indicated in Fig. $10\left(\mathrm{C}_{0}=0.025\right.$ to $0.100 \mathrm{a} / \mathrm{o}$ 으 in Ta). These data show that for high oxygen concentrations in sodium, i.e., above $\sim 7 \mathrm{ppm} \underline{\mathrm{O}}$, the temperature dependence of $\mathrm{K}_{\mathrm{p}}$ for oxygen solution remains constant. For oxygen concentrations below $7 \mathrm{ppm}$, the activation energy for the solution process can be considerably less than the $22.3 \mathrm{kcal} /$ mole observed at the higher oxygen concentrations. These curves also show that we can have the same rate constant at two different temperatures. For example, at 1 ppm oxygen in sodium, the rate constant in Fig. 10 a has approximately the same value at 500 and $700^{\circ} \mathrm{C}$. The curves in Figs. 9 and 10 for oxygen concentrations in sodium above $5 \mathrm{ppm}$ are terminated at temperatures below which oxide film formation is expected. These temperatures can be obtained from Fig. 5 for the various oxygen concentrations in sodium. 


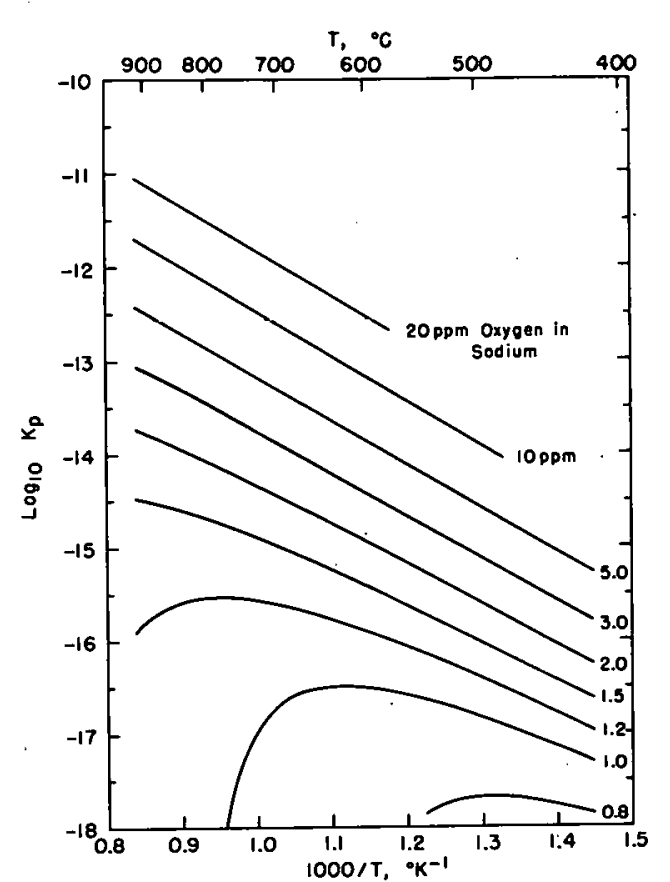

(a) $\mathrm{C}_{0}=0.025 \mathrm{a} / \mathrm{o}(22.1 \mathrm{ppm})$ Oxygen in Tantalum

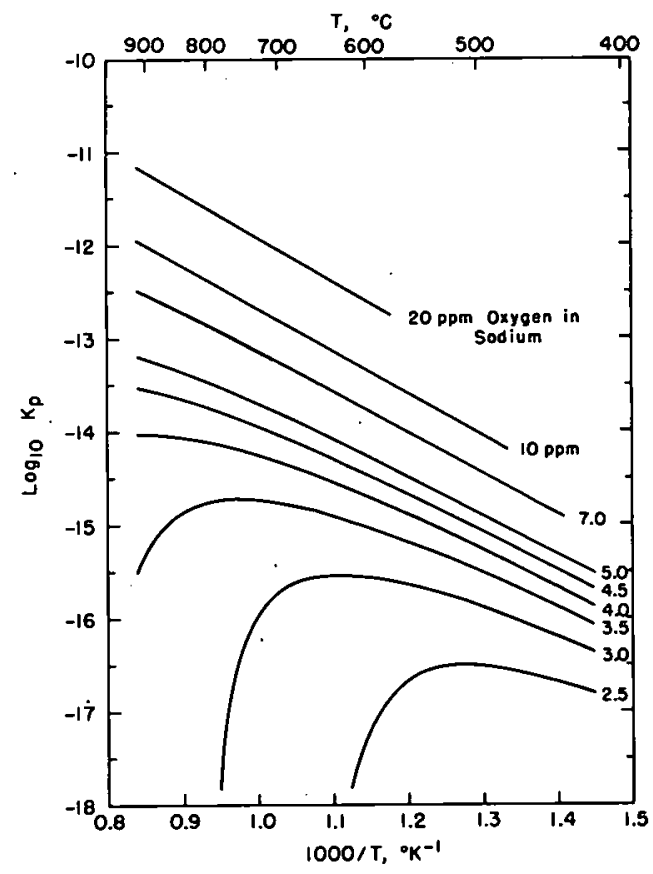

(c) $\mathrm{C}_{0}=0.075 \mathrm{a} / \mathrm{o}(66.4 \mathrm{ppm})$ Oxygen in Tantalum

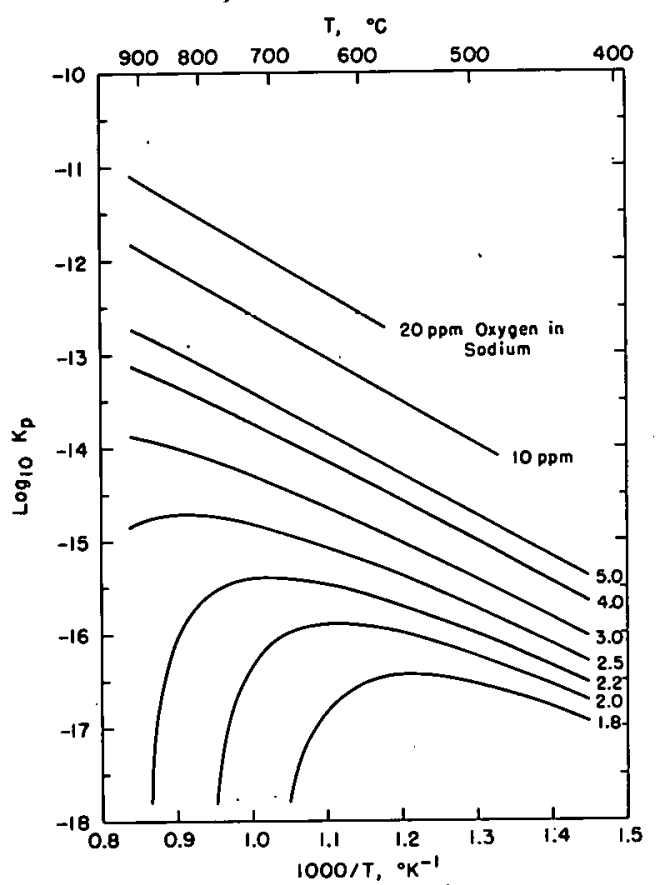

(b) $\mathrm{C}_{0}=0.050 \mathrm{a} / \mathrm{o}(44.2 \mathrm{ppm})$ Oxygen in Tantalum

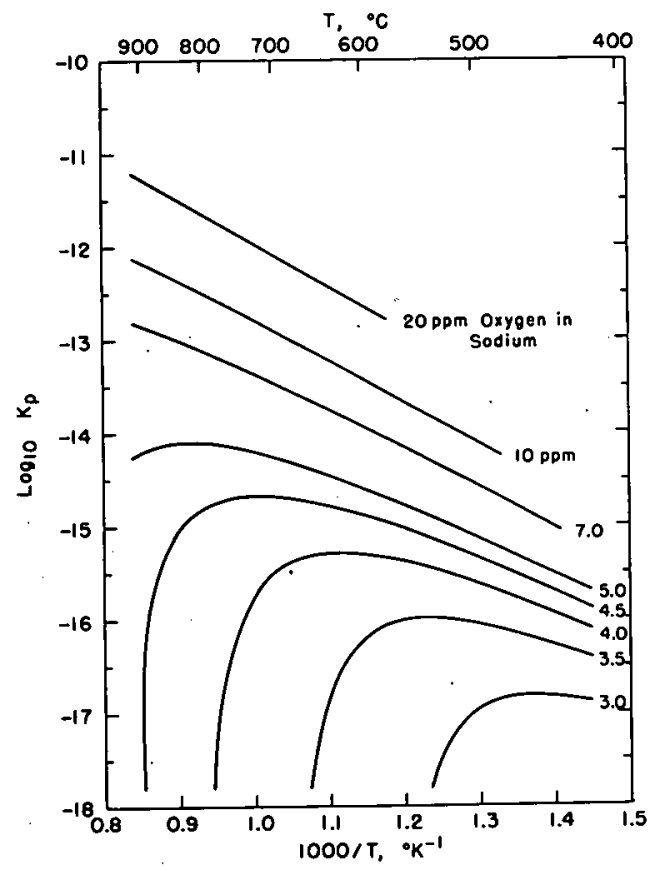

(d) $C_{0}=0.100 \mathrm{a} / \mathrm{o}(88.5 \mathrm{ppm})$ Oxygen in Tantalum

Fig. 10. Temperature Dependence of the Parabolic Rate Constant for Oxygen Solution in Tantalum with Initial Oxygen Contents of $0.025,0.050,0.075$, and $0.100 \mathrm{a} / \mathrm{o}$ Oxygen. The parabolic rate constant is in units of $\mathrm{g}^{2} \underline{\mathrm{O}} / \mathrm{cm}^{4}$-sec. 
The results of the calculations are further correlated in Fig. 11, where the rate constant is plotted as a function of initial oxygen concentration in tantalum for several temperatures in the range of interest. Figure 11 shows the strong dependence of the rate constant on the initial oxygen concentration in tantalum at low oxygen concentrations in sodium. It also shows that, with increasing temperature, the rate constant becomes more sensitive to initial oxygen concentration in tantalum. However, at the higher oxygen levels in sodium, the rate constant is relatively insensitive to the initial oxygen concentrations in tantalum.

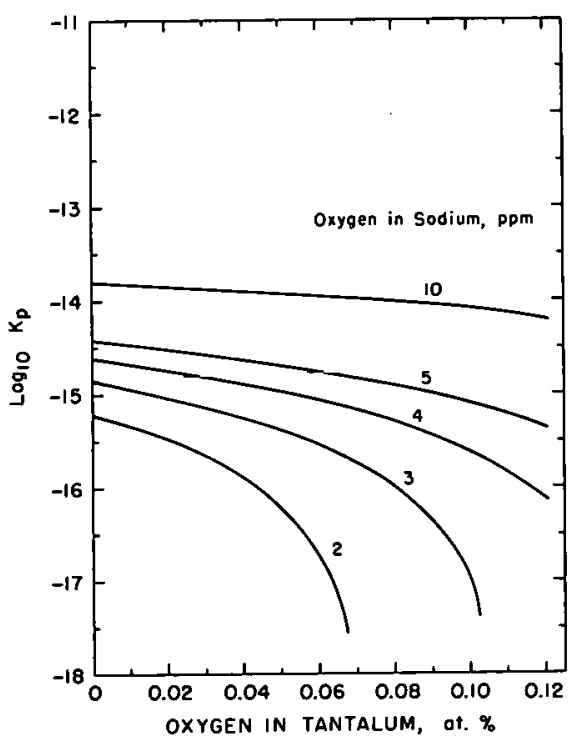

(a) $\mathrm{T}=500^{\circ} \mathrm{C}$

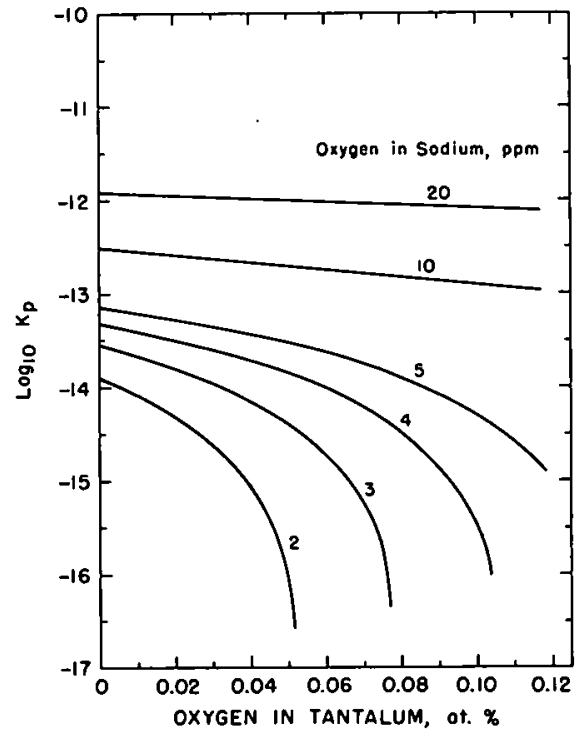

(c) $\mathrm{T}=700^{\circ} \mathrm{C}$

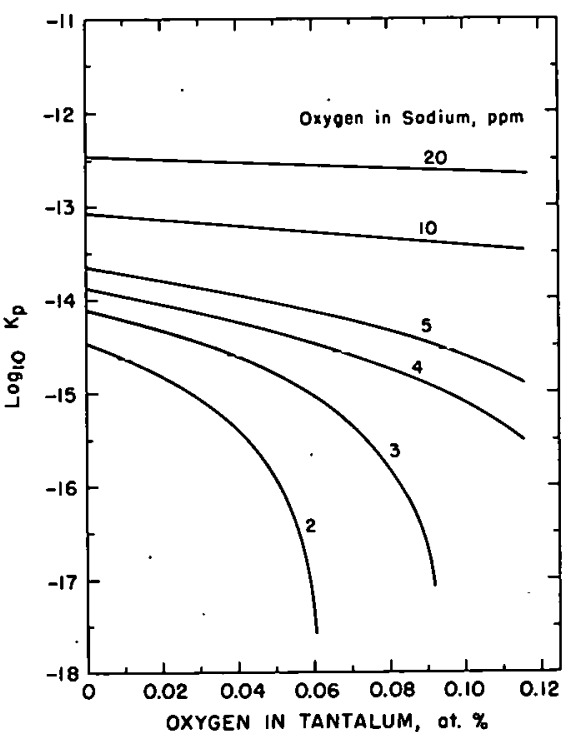

(b) $\mathrm{T}=600^{\circ} \mathrm{C}$

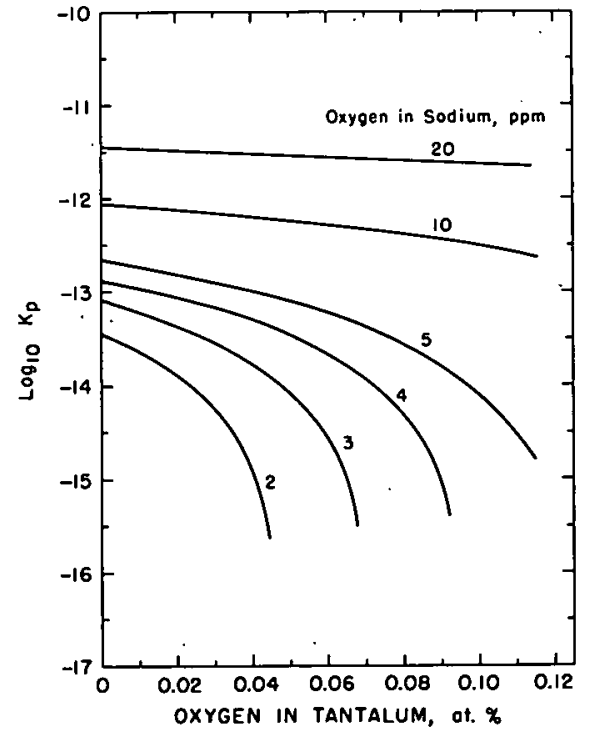

(d) $\mathrm{T}=800^{\circ} \mathrm{C}$

Fig. 11. Effect of Initial Oxygen Concentration in Tantalum on the Parabolic Rate Constant for Oxygen Solution in Tantalum at $500,600,700$, and $800^{\circ} \mathrm{C}$. The parabolic rate constant is in units of $\mathrm{g}^{2} \underline{\mathrm{O}} / \mathrm{cm}^{4}-\mathrm{sec}$. 
Similar calculations have been carried out for the niobium-oxygensodium system. Figure 12 is a plot of $\log K_{p}$ versus reciprocal temperature for zero initial oxygen concentration in niobium $\left(C_{0}=0\right)$. The activation energy for solution of oxygen in niobium exposed to sodium, as determined from Eq. 25 , is $16.5 \mathrm{kcal} / \mathrm{mole}$, which is somewhat less than the value of $22.3 \mathrm{kcal} /$ mole calculated for oxygen solution in tantalum. Comparison of the $K_{p}$ values for niobium and tantalum in Figs. 12 and 9 , respectively, indicates that, at a given oxygen concentration in sodium, the solution rate constant for oxygen in niobium is about an order of magnitude greater than for tantalum.

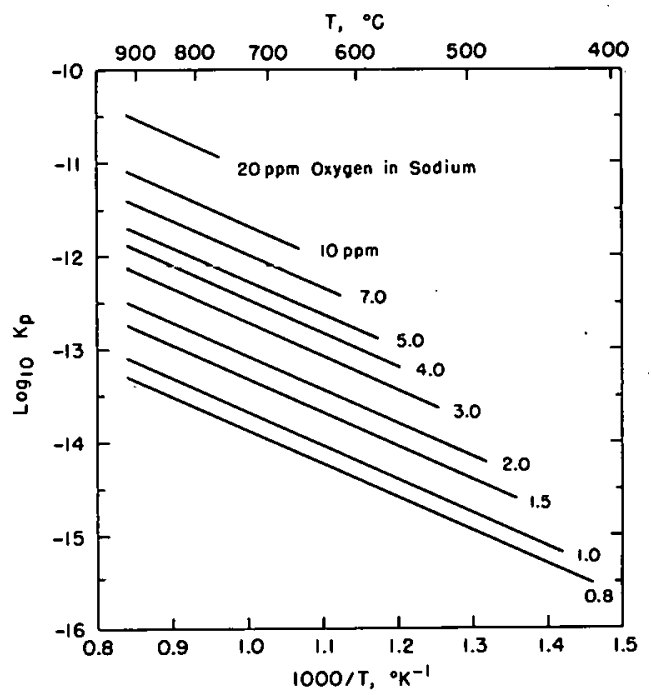

Fig. 12

Temperature Dependence of the Parabolic Rate Constant for Oxygen Solution in: Niobium with Zero Initial Oxygen Content, i.e., $C_{0}=0$. The parabolic rate constant is in units of $\mathrm{g}^{2} \mathrm{O} / \mathrm{cm}^{4}$-sec.

Figure 13 shows the effect of initial oxygen concentration in the niobium on the rate constant. The shapes of these curves are similar to those for tantalum. However, at the same oxygen concentrations in sodium, the temperatures at which the maxima in the rate constants occur are higher for niobium than for tantalum. For comparable conditions, the curves show that the rate constant for niobium is considerably higher than for tantalum. Note also that, because of $\mathrm{NbO}$ film formation, the rateconstant curves terminate at higher temperatures for niobium. The temperatures at which $\mathrm{NbO}$ forms at the various oxygen concentrations in sodium can be obtained from Fig. 6.

The curves in Fig. 14 correlate the data for several temperatures in the range of interest. Comparison of these curves with Fig. 11 indicates that, at the same oxygen concentration in sodium, the rate constant is less sensitive to initial oxygen in niobium than for tantalum. The higher oxygen concentrations in sodium are not included in these plots because oxide film formation occurs. 


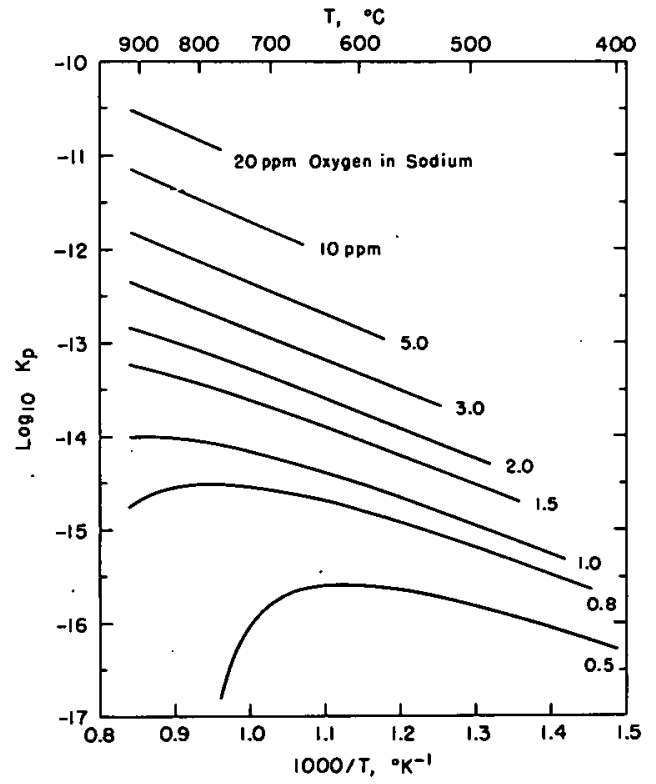

(a) $C_{0}=0.025 \mathrm{a} / \mathrm{o}(43 \mathrm{ppm})$ Oxygen in Niobium

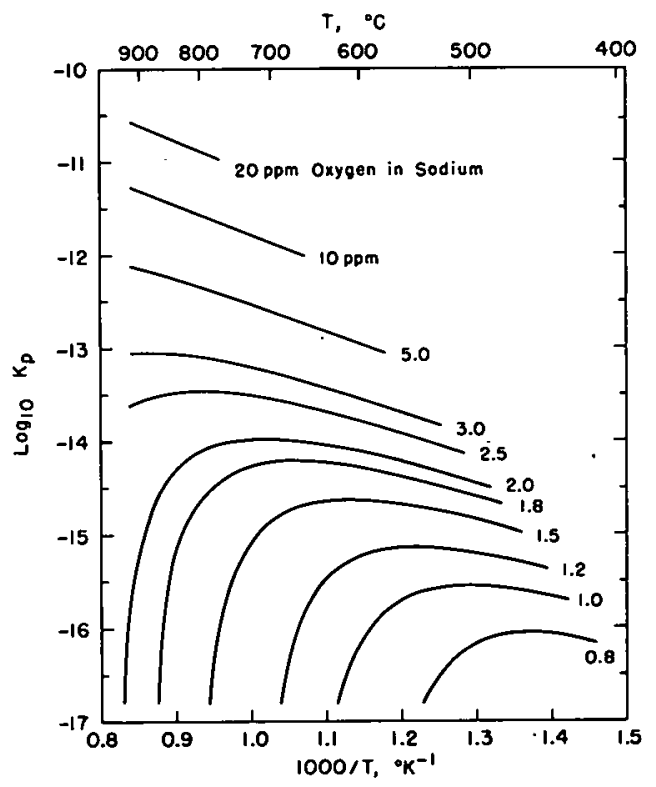

(c) $\mathrm{C}_{0}=0.075 \mathrm{a} / \mathrm{\circ}(129 \mathrm{ppm})$ Oxygen in Niobium

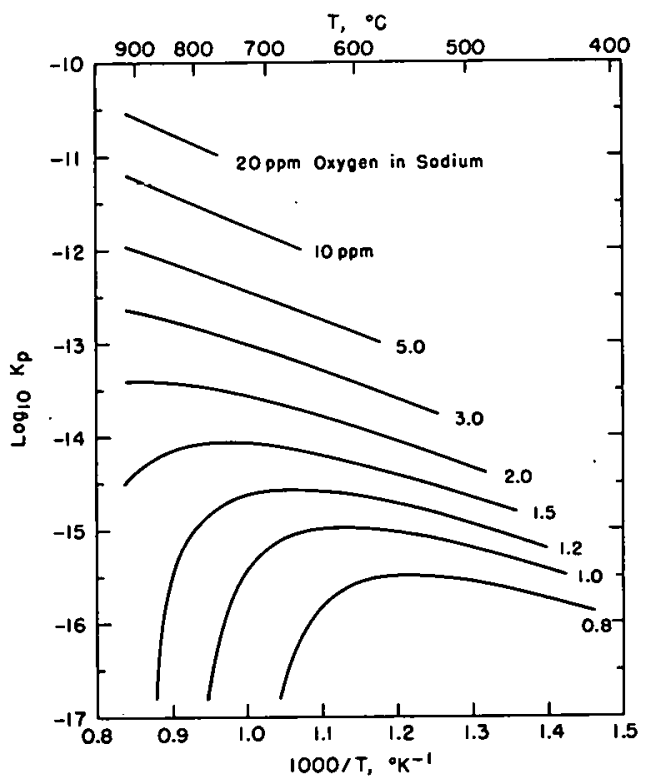

(b) $C_{0}=0.050 \mathrm{a} / \mathrm{o}(86 \mathrm{ppm})$ Oxygen in Niobium

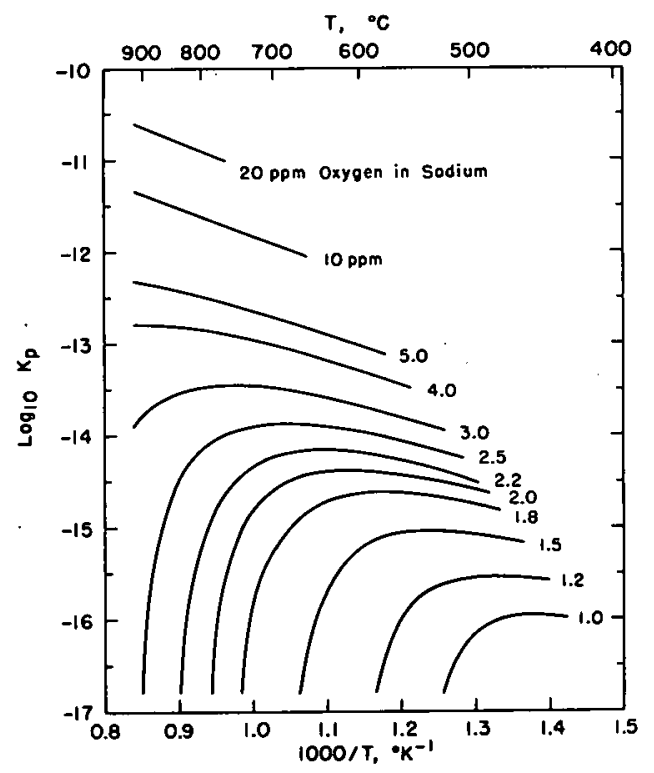

(d) $C_{0}=0.100 \mathrm{a} / \mathrm{o}(172 \mathrm{ppm})$ Oxygen in Niobium

Fig. 13. Temperature Dependence of the Parabolic Rate Constants for Oxygen Solution in Niobium with Initial Oxygen Contents of $0.025,0.050$, 0.075 , and $0.100 \mathrm{a} / \mathrm{o}$ Oxygen. The parabolic rate constant is in units of $\mathrm{g}^{2} \mathrm{O} / \mathrm{cm}^{4}$-sec. 


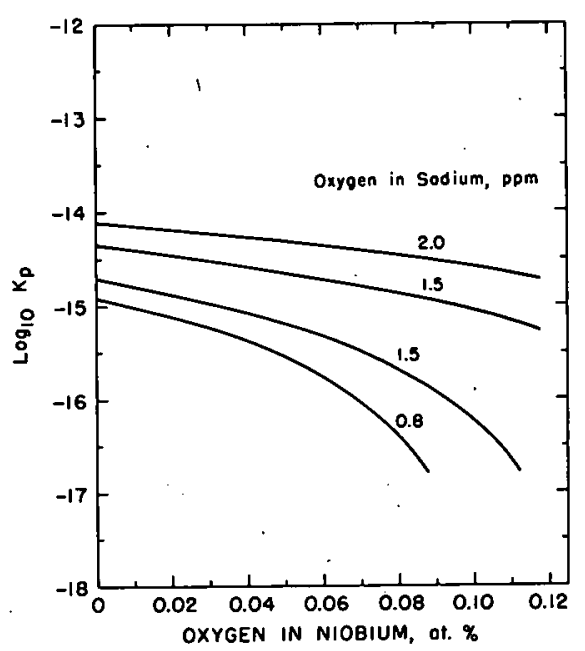

(a) $\mathrm{T}=500^{\circ} \mathrm{C}$

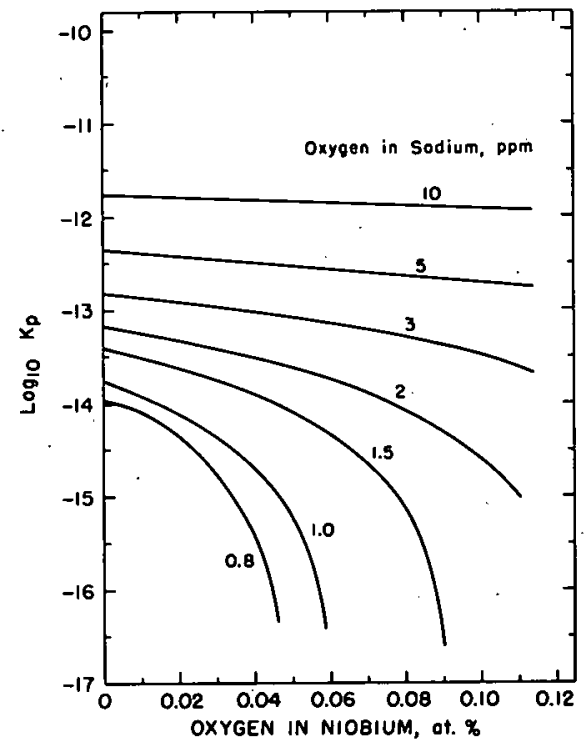

(c) $\mathrm{T}=700^{\circ} \mathrm{C}$

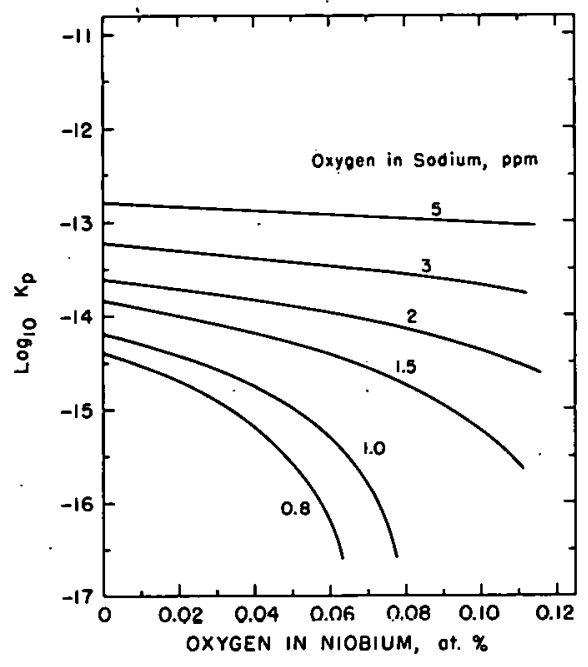

(b) $\mathrm{T}=600^{\circ} \mathrm{C}$

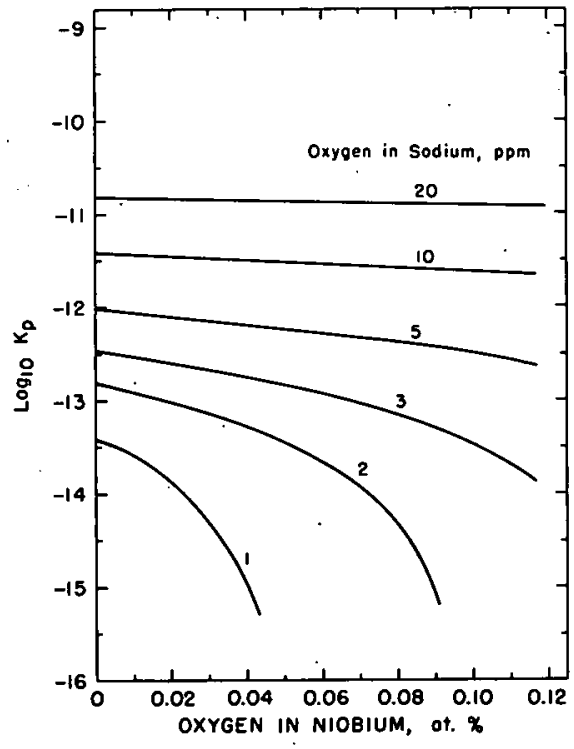

(d) $\mathrm{T}=800^{\circ} \mathrm{C}$

Fig. 14. Effect of Initial Oxygen Concentration in Niobium on the Parabolic Rate Constants for Oxygen Solution in Niobium at 500,600,700, and $800^{\circ} \mathrm{C}$. The parabolic rate constant is in units of $\mathrm{g}^{2} \underline{\mathrm{O}} / \mathrm{cm}^{4}-\mathrm{sec}$. 


\section{DISCUSSION}

The phase equilibria in Figs. 5 and 6 are very dependent upon the calculated distribution coefficients for oxygen between the refractory metals and liquid sodium. The data for the solubility of oxygen in tantalum, niobium, and sodium used in the calculations are reliable, as are the data for the standard free energies of formation for the oxide phases. At this point, any significant error in the calculated distribution coefficients would have to be attributed to the questionable assumption that oxygen in the refractory metals and/or sodium obeys Raoult's law. Few solutions behave ideally. For this reason, the distribution coefficients will have to be determined experimentally to accurately fix the phase-equilibria curves in Figs. 5 and 6. Depending upon the agreement between the calculated and experimentaldistribution coefficients, it may be warranted to try to apply thermodynamic solution models to the oxygen solubility data to determine the degree of nonideality in these systems. The success of this latter approach would depend upon the availability of heats and entropies of fusion for the oxide phases $\left(\mathrm{Na}_{2} \mathrm{O}, \mathrm{Ta}_{2} \mathrm{O}_{5}\right.$, etc.).

The distribution coefficients would also have to be determined accurately before quantitative significance could be attached to the parabolic rate constants for oxygen solution in tantalum or niobium. The surface concentration, $C_{s}$, for a given oxygen concentration in sodium was obtained directly from the distribution coefficient at each temperature.

Although the above limitations are recognized, the results have been useful in specifying experimental conditions for distribution-coefficient studies in these systems. The curves in Figs. 5 and 6 provide limits on temperature and oxygen concentration in sodium for the two-phase equilibria (metal-sodium). Also, on the basis of the calculated surface concentrations for oxygen in the refractory metal, minimum equilibration times can be estimated for wire samples used in internal friction analysis for nonmetallic impurities $(O, N, C$, etc.).

The results in Figs. 5 and 6 have further implications in the design of both isothermal and athermal corrosion experiments. For example, if the temperature dependence of the "corrosion rate" of niobium were determined at $10 \mathrm{ppm}$ oxygen in sodium in an isothermal system, a change in the reaction process may occur at $\sim 650^{\circ} \mathrm{C}$. Figure 6 indicates that above $\sim 650^{\circ} \mathrm{C}$ for the above conditions, the sample-liquid interface would correspond to $\mathrm{Nb} / \underline{\mathrm{O}}_{\mathrm{Na}}$, and below $\sim 650^{\circ} \mathrm{C}$ the sample-liquid interface would be $\mathrm{NbO} / \mathrm{Q}_{\mathrm{Na}}$. Thus, as the temperature is decreased from 700 to $500^{\circ} \mathrm{C}$, the predominant reaction process may change from one of metal dissolution or oxygen solution in niobium to metal oxidation. A similar situation would exist in an athermal loop experiment with a hot leg at $700^{\circ} \mathrm{C}$ and a cold leg at $500^{\circ} \mathrm{C}$. In the high-temperature portion of the system, niobium would be the stable 
phase in contact with the liquid; in the cold regions in the system, NbO would become stable. Thus, as the liquid passes to cooler regions in the system, niobium in solution in sodium could be oxidized to $\mathrm{NbO}$ by way of a homogeneous reaction in the liquid phase. A process of this type could have important bearing on the kinetics of the corrosion reaction in the hot leg.

The data for the parabolic rate constants for oxygen solution in tantalum and niobium, plotted as a function of reciprocal temperature at specified oxygen concentrations in sodium, place in perspective the degree to which the oxygen content of sodium must be controlled to obtain meaningful experimental results. The curves also indicate the necessity for accurate determinations of the oxygen content of the sodium. While niobium and tantalum are reported to lose weight in sodium corrosion experiments, and weight gain due to oxygen solution in these metals may be of secondary importance, the above observations are directly applicable to studies involving vanadium and vanadium alloy.s. These materials have exhibited weight gains as a result of oxygen solution in a low oxygen sodium environment. ${ }^{21}$ Similar calculations on the $\mathrm{V}-\mathrm{O}-\mathrm{Na}$ system are not possible at this time because of the lack of appropriate thermodynamic data.for the system. 


\section{REFERENCES}

1. Rutkauskas, V. J., USAEC Report LA-3524-MS (1966).

2. Noden, J. D., and Bagley, K. A., UKAEA Report TN-80 (1958).

3. Gebhardt, E., and Seghezzi, H. D., Z. Metallk. 50, 521-527 (1959).

4. Gebhardt; E., and Rothenbacher, R., Z. Metallk. 54, 623-630 (1963).

5. Lenel, F. V., Regitz, L. J., and Hulsizer, W. R., AROD-2530-1 (1962).

6. Lene1, F. V., and Hulsizer, W. R., AROD-2530-2 (1963).

7. Worrell, W. L., Proceedings of the Symposium on Thermodynamics, Vol. 1, pp. 131-143, IAEA, Vienna (1965).

8. Hansen, M., and Anderko, K., Constitution of.Binary AZloys, pp. 10671068, McGraw-Hill, New York (1958):

9. Lagergren, S., and Magneli, A., Acta. Chem. Scand. 6, 444-446 (1952).

10. Hoch, M., and Mathur, M., J. Amer. Ceram. Soc. 45, 373-375 (1962).

11. Kofstad, P., J. Electrochem. Soc. 109, 776-781 (1962).

12. Raines, G. E., Weaver, C. V., and Stang, J. H., BMI-1284 (1958).

13. Evans, J. W., and Thorley, A., UKAEA Report IGR-TN/C-1019 (1958).

14. Peterson, N. L., WADD-TR-60-973 (1960).

15. Gebhardt, E., Seghezzi, H. D., and Stagherr, A., Z. Metallk. 48, 624-627 (1957).

16. Ang, C. Y., Acta. Met. 1, 123-125 (1953).

17. Gulbransen, E. A., and Andrew, K: F., Trans. AIME 188, 586-599 (1950).

18. Powers, R. W., and Doyle, M. V., Acta. Met. 4, 233-242 (1956).

19. Powers, R. W., and Doyle, M. V., J. App1. Phys. 30, 514-524 (1959).

20. Kofstad, P., J. Less-Common Metals 7, 241-266 (1964).

21. Greenberg, S., Ruther, W. E., and Levin, H. A., Symposium on Alkali Metal Coolants, IAEA; Vienna (1966), pp. 63-84. 


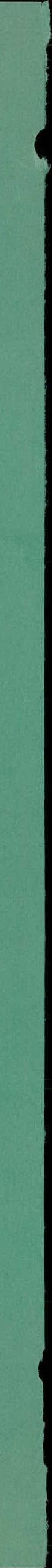

